\title{
EXTRACTION AND EFFECT OF MORDATING METHOD ON DYE ABSORBTION OF NATURAL DYE EXTRACTION FROM ALCANNA ON REGENERATED FIBRE
}

\author{
FIONA PAULSON. $T^{1} \&$ R. DIVYA ${ }^{2}$ \\ ${ }^{1}$ M.Phil Scholar, PSG College of Arts and Science, Coimbatore, Tamil Nadu, India \\ ${ }^{2}$ Assistant Professor, PSG College of Arts and Science, Coimbatore, Tamil Nadu, India
}

\begin{abstract}
Nature is full of wonderful colours and people has been exploring on different coloured garments, food and many other daily use products according to trend. There has been evidence from the ancient reports and writers that there they were used in all times and nearly thousands of natural sources of dyes. There is always a trend and separate demand for eco-friendly products in the international market and its easily possible to master the techniques of dyeing using natural dyes. In a search for newer natural sources and techniques attempts, dye has been extracted from selected Alkanna and its applied on the regenerated fibre yarn "bamboo" with Quercus Infectoria natural mordant. Effect of the dyeing, methods of extraction and the mordant has been visualized on the strength of colour and its fastness properties of the dyed sample. In bamboo, regarding its general appearance the sample dyed with tree bark using Quercus Infectoria mordant with pre-mordating technique was rated "good". Texture and lusture of the sample was rated as good and medium respectively. The weight of the sample has maximum increase level from its orginal weight dyed with Quercus Infectoria mordant by using the pre-mordant technique has maintained the fabric thickness of the fibre yarn, it has also increased the strength of the fibre. The colourfastness of the dyed bamboo sample with Alkanna.had very good light fastness with pre-mordating technique. In general the sample that has been dyed using the following technique has good to excellent colour fastness to both wet and dry crocking with good colourfastness resistance to washing. Colour to the attire or fibre gives a pleasant look to the substrate product, but also express ideas of the wearer. Though the existence of colour remains from decades the extracting technique and usage of colour remains from India. People demand colours for the expressive idea of one self and for decoration purpose also. In many years there has been an interest towards eco-friendly and natural dyes. The main reason for the usage of these techniques are they are bio-degradable and higher compatibility with the environmental advantages with lower toxity and allergies comparative to synthetic dyes. In this study of natural dyes and colour that are extracted from tree bark called Alkanna and to apply on textile material with Quercus Infectoria mordants. These natural dyes also give some medicinal values and properties also.
\end{abstract}

KEYWORDS: International market, Eco Friendly, Demand

Received: Jun 10, 2020; Accepted: Jun 30, 2020; Published: Aug 04, 2020; Paper Id.: IJMPERDJUN2020617

\section{INTRODUCTION}

Colour is one of the major element of nature that made human living life more energetic and fascinating in the world. They are supposed to be connected with emotions, quality, seasons, festivals and passionate. Colour the main element that highlights the entire fibre fabric. The usage of colour is one of the most important process in the fabric development and make, it was the result for the beauty the colouring matters from natural sources such as plant,minerals and animals. The term Natural Dyes covers all the dyes from natural resources says Rathi and Padhye in the 1990's. The discovery of synthetic dyes was found soon used by many markets around the 
world, which was over placed by the use of natural dyes and also took over the dependency of India from where natural dyes were the source says Knur in 1996. The arts of natural dyes has gained not only safety for health and also for the environment states V.K.I.T. Katyayini., natural dyes are safer with no hazards, easy dispose, Eco-friendly, and some with medicinal properties. Those type of fabrics are called as Smart textiles or Ayur Fabric materials.

Almost many synthetic dyes have its originality from Coal cause they where easily available and also easy to dispose. Synthetic dyes involve the use of hazardous chemicals that harm the environment during the usage process, which are harmful for human skin and health issues in the environment.

Natural dyes realized worldwide for its eco-friendly nature, easy application and large availability of the source. Many methods are used for extraction and application of these natural dyes globally, they are also tried on different fabric materials in the textile market. In this work Alkanna dye and application in done on materials and different shades have been obtained on the regenerated material bamboo using Quercus Infectoria natural mordant method and mordanting method (pre-mordating) the dye has been carried on the fibre. Fastness properties of the dye sample has also been analysed.

\section{OBJECTIVES OF THE STUDY}

- Understanding eco-friendliness of natural dyes extraction from Alkanna

- To application of natural dye on Bamboo fibre with Quercus Infectoria mordant technique

- To analyse the fastness and strength property of the dyed sample

\section{EXPERIMENTAL PROCEDURE}

\section{Selection of the Fibre}

The selected fibre is the Regenrated Bamboo fibre. Bamboo fibers are also called as cellulose fiber that are extracted or from natural bamboo, but they vary from each bamboo plant variety. Bamboo can be cultivated very easily and quickly, and can also be used as a cash crop in some regions of the world. It is a regenerated fibre form which is cultivated in the greenhousesIn China and Japan, thin strips of this bamboo were woven together to make hats and shoes. One particularly designed bamboo hat was a part of the rural life, which was worn by most farmers and fishermen for them to be protected from the sun. In the West, bamboo onetime used as a structural component in corsets, bustles and other types of elements in the fashionable woman's dresses, like the other cellulose-based clothing fiber materials, bamboo fiber is biodegradable in soil with the help of micro organisms and sunlight. Clothing made from bamboo can be disposed in any organic and environmentally manner. Bamboo leaves and the soft inner pith of the hard bamboo trunk was extracted using the wet process and then mechanically crushed to the extract the fibre form "the cellulose", and adds carbon disulfide to form "xanthenes". After a particular period of time, temperature and various other inorganic and organic additives (including some amount of air in contact) determining the final temperature of polymerization, the xanthenes cellulose releases dithiocarbonic acid that will later decomposes to carbon and water. Bamboo fabric is now used for tailoring many loose fitting garments in the clothing industry. 


\section{EFFECTS OF MORDATING ON NATURAL DYE ABSORPTION}

\section{Bleaching of Yarn Sample}

If a clear and evenly spread of dyed colour is required after the process of dyeing bleaching is essential. For the bleaching technique and chemicals are used make a dye bath using the following in a stainless steel vessel. Use water in the ratio of 1:30 or 4 litres of water will be needed for 100 grams of bamboo sample.

Table 1

\begin{tabular}{|l|l|}
\hline Sodium Hypo Chloride & \multicolumn{1}{|c|}{$\mathbf{1 \%}$} \\
\hline Sodium Chloride & $1 \%$ \\
\hline Temperature & $100 \mathrm{C}$ \\
\hline Time & $11 / 2 \mathrm{hrs}$ \\
\hline M:L ratio & $1: 60$ \\
\hline $\mathrm{pH}$ & 11.4 \\
\hline
\end{tabular}

Add the wetted sample into the vessel in the dye bath for 2-3 hrs, turn them evenly and occasionally with a glass rod which is clean. Make sure the sample is completely immersed in the dye bath, remove the sample from the bleach and show them under cold running water rinse thoroughly. Expose to dry the sample in air, after the process white colour sample will be obtained.

\section{Selection of Dye}

The bark of the tree Alkanna were selected as the dye source selected for the study on their availability for getting the shades. The botanical name of the dye are also a part from which the dye is extracted from the source.

Table 2

\begin{tabular}{|l|l|}
\hline \multicolumn{2}{|c|}{ Binomial Name and Details } \\
\hline Family & Boraginaceae \\
\hline Genus & Alkanna \\
\hline Species & A. tinctoria \\
\hline
\end{tabular}

\section{Selection of Mordant}

Natural dyes need a chemical in the form of a metal for its fixation of the dye evenly on the fibre. This chemical is known as Mordant. The mordant help in better fixation and obtain faster production of shades by forming an insoluble component of mordant and the dye stuff with the fibre. Natural mordant are more eco-friendly, so usage of Quercus Infectoria mordant makes the process more eco-friendly on the selected study. 
Table 3

\begin{tabular}{|l|l|}
\hline \multicolumn{2}{|c|}{ Binomial Name and Details } \\
\hline Family & Gallinut \\
\hline Genus & Quercus Infectoria \\
\hline Species & Fruit \\
\hline
\end{tabular}

Table 4: Nomenclature of the Sample

\begin{tabular}{|c|l|}
\hline Particulars & \multicolumn{1}{|c|}{ Abbreviation } \\
\hline $\mathrm{B}$ & Bamboo \\
\hline $\mathrm{Q}_{1}$ & Quercus Infectoria \\
\hline $\mathrm{P}_{2}$ & Pre-Mordant \\
\hline
\end{tabular}

$\mathrm{BQ}_{1} \mathbf{P}_{2}$

B indicates Bamboo, the name of the material used for study

$\mathrm{Q}_{1}$ indicates the mordant used respectively Quercus Infectoria

$\mathrm{P}_{2}$ indicates the mordant technique used for pre-mordant

\section{DYEING}

\section{Preparation of the Dye}

The Alkanna was collected and they were dried in the shade. The dried bark are used for dyeing.

\section{EXTRACTION METHOD}

To extract the dye the following methods are followed.

Amount of dye powder was taken according to the sample weight. The dyed powder was boiled in water with M:L ratio 1:10 for half an hour after that the dye solution is filtered.

\section{The Dyeing Methods are followed:}

\section{A. Alkali Method}

Alkali method of dye extraction was by taking 5 grms of dyed powder to $100 \mathrm{ml}$ of water container with 1 grm of alum for 1 grm of sample yarn for half an hour.

\section{Mordanting}

The selected mordant is Quercus Infectoria., the selected mordant technique are pre-mordanting.

\section{Pre-Mordanting}

Weight of the fibre sample were first mordated then dyed 


\section{Mordanting Conditions}

Mordant used - Quercus Infectoria

Concentration - $2 \%$

Salt $-2 \%$

Temperature - 90C

Time - 30min

M:L - 1:10

\section{DYEING CONDITIONS}

Dye used - Alkanna

Dye condition - $2 \%$

Salt $-2 \%$

Temperature - 90C

Time - 30min

M:L - 1:10

\section{ACTUAL DYEING}

Pre-treatment process includes 10 grm of Quercus Infectoria natural mordant that has been diluted with $40 \mathrm{ml}$ of soft water in a vessel along with the yarn fibre for absorbency of the mordant for about $30 \mathrm{~min}$ in $27^{\circ}$ temperature, they are then continuously stirred for even spread and fixation its also to avoid patchiness after the pre-mordant method for the required time the dyeing process is followed by adding $15 \mathrm{ml}$ of soft water in the ratio 1:40 M:L with the dye substance of $40 \mathrm{ml}$ (dye is extracted from powder to extraction form) to the exciting solution and evenly stirred which is then kept in $50^{\circ}$ temp for 15 min in the later stages the temperature is increased to $75^{\circ} \mathrm{kept}$ for $25 \mathrm{~min}$ which is the boiling stage temperature which will help allowed the yarn to absorb the dye better. After the required time is gained the lea is taken from the vessel and washed under cold running water then left to dry in shadow.

The same procedure was followed and the sample was gained.

\section{Laboratory Tests Evaluation}

The natural dye sample were evaluated as follows:

\section{Visual Evaluation}

A panel of 18 postgraduate students who are from the same field of costume design and fashion was selected for rating the samples. General appearance, bright colours, evenness of the dye, lusture and texture were the main aspect for the testing in the visual evaluation. 


\section{Single Yarn Tester}

The single yarn tester was measured using the Single yarn strength tester works on the principle of constant rate of elongation [CRE] with pneumatic base which is powered by micro controller; it's a semi automatic user friendly instrument, its traverse speed and specimen length setting can be adjusted through data entry, quick lowering of upper jaw results fast testing.

\section{COLOUR FASTNESS}

Color fastness is the resistance of color to fade or wash away the dye that is dye dyed on the material or fiber yarn. It is an important to measure the quality of the dyed product with the following tests.

$$
\begin{aligned}
& \text { Colour Fastness to Washing } \\
& \text { Colour Fastness to Light } \\
& \text { Colour Fastness to Rubbing }
\end{aligned}
$$

\section{Colour Fastness to Washing}

In the washing test, the change in color of the fibre A 10 strand lea of yarn was taken for the pilot study testing for the test was taken and the wash test was followed

The solution for the washing is prepared to the required temperature for washing. The liquor material ratio is 50:1 was prepared. After soaping treatment, remove the sample, rinse in cold water and then with running cold water under a running tap. Squeeze it and shadow dry at a temperature not more than $60^{\circ} \mathrm{C}$. The change in color of the yarn dye is evaluated with the help of a Grey scales and the changes are noted, this method can be followed for more wash efficiency tests like 2 wash, 4 wash, 6 wash etc.

\section{Colour Fastness to Light}

Major test is done using the light as hue when exposed to the sample, it sometimes turns lighter or darker. A small sample of the yarn was divided into 8 divisions of 1 inch each in a sqaure width with a strip of chart paper over them. The chart paper is then fixed to holder that is clamped with the xenon-test altas machine. After six hours of exposure the comparison is done with the grey scale.

\section{Colour Fastness to Rubbing:}

Rubbing color fastness refers to the ability to sustain of original color of dyed yarn when rubbing. Dry rubbing color fastness mention the fading of dyed fabric when rubbed with a standard white cloth.

There are 2 types of rubbing techniques

- Wet rubbing

- Dry rubbing

Wet rubbing color fastness refers to the situation of fading of dyed yarn when rubbed with a standard white cloth which is wet with the help of water. The main aim of Rubbing color fastness depends on the staining of white cloth. After testing, the white cloth is compared to staining sample cards to measure the fastness. Rubbing color fastness, same as washing color fastness that is divided into 5 grades and 9 files, among which grade 5 is the best and grade 1 is the worst. The 
friction makes the fading of yarn with dye fade off by method of friction. Wet rubbing is influenced by both external force and water, so it is about one level lower than dry rubbing. On the other hand dry rubbing is the method of rubbing with the help of a standard white cloth which is kept dry and the same method is followed for the test and they are recorded.

\section{RESULTS AND DISCUSSIONS}

\section{Visual Evaluation}

The result of the visual evaluation of Bamboo fibre yarn sample are presented:

Table 5

\begin{tabular}{|c|c|c|c|c|}
\hline Samples & General Appearance & $\begin{array}{c}\text { Brightness } \\
\text { of Colour }\end{array}$ & Texture & Lusture \\
\hline L $\mathbf{P}_{\mathbf{1}} \mathbf{P}_{\mathbf{2}}$ & Good Fair Poor & Bright Medium Dull & Finemedium Coarse & Good Fair Poor \\
\hline & 76200 & 71320 & 22740 & 0920 \\
\hline
\end{tabular}

The general aspects was visually evaluated. The sample is good above $75 \%$ to $90 \%$ of the fair by $55 \%$.The brigthness of the sample was evaluated and was considered good by $62 \%$ to $82 \%$ and fair by $40 \%$ to $60 \%$.The sample was evenly dyed the texture and the luster was good.

\section{Laboratory Test}

The sample strength of bamboo yarn is shown in the table

\section{Yarn Strength}

Table 6

\begin{tabular}{|c|c|c|c|c|}
\hline S. No & Sample & $\begin{array}{c}\text { Strength } \\
\text { (Ounce/Grm W) }\end{array}$ & $\begin{array}{c}\text { Gain or Loss } \\
\text { (Over Orginal) }\end{array}$ & \% of Gain or Loss \\
\hline 1. & Orginal & 100.2 & 0 & - \\
\hline 2. & $\mathrm{LP}_{1} \mathrm{P}_{2}$ & 130 & +25.1 & 25.1 \\
\hline
\end{tabular}

On dyeing with the natural colour on the sample the strength of the sample has been increased. The dyed sample was rated second and the rest was rated low. This shows that the sample when dyed from the original the strength increases.Use of the natural mordant has also supported in increasing the sample weight with the dye.

Table 7: pH Value Test

\begin{tabular}{|c|c|c|c|}
\hline S. No & Sample & Ph Value & Result \\
\hline 1 & $\mathrm{LP}_{1} \mathrm{P}_{2}$ & 7.0 & FAIR \\
\hline
\end{tabular}

Table 8: Colour Fastness Test

\begin{tabular}{|c|c|c|c|c|}
\hline Sample & $\begin{array}{c}\text { Colour Fastness to } \\
\text { Light }\end{array}$ & $\begin{array}{c}\text { Colour Fastness to } \\
\text { Washing }\end{array}$ & $\begin{array}{c}\text { Colour Fastness to } \\
\text { Rubbing (Dry) }\end{array}$ & $\begin{array}{c}\text { Colour Fastness to } \\
\text { Rubbing (Wet) }\end{array}$ \\
\hline & & Color Stain Change & Colour Stain Change & Colour Stain Change \\
\hline LPP & 3.5 & $2 / 34$ & $3.5 / 55$ & $44 / 5$ \\
\hline
\end{tabular}




\section{Colour Fastness Test- Bamboo}

Table 9: Abstract and Results

\begin{tabular}{|c|l|c|}
\hline S. No & \multicolumn{1}{|c|}{ Sample Name } & $\mathbf{L q}_{1} \mathbf{p}_{\mathbf{2}}$ \\
\hline 1 & General appearance & 76 \\
\hline. & Brightness & 69 \\
\hline 3 & Texture & 22 \\
\hline 4 & Luster & 11 \\
\hline 5 & Fastness to light & 3.5 \\
\hline 6 & Fastness to washing & $2 / 3$ \\
\hline 7 & Fastness to rubbing (dry) & $3.5 / 5$ \\
\hline 8 & Fastness to rubbing (wet) & $4 / 5$ \\
\hline 9 & Yarn strength & 25.1 \\
\hline 10 & pH value & 7 \\
\hline
\end{tabular}

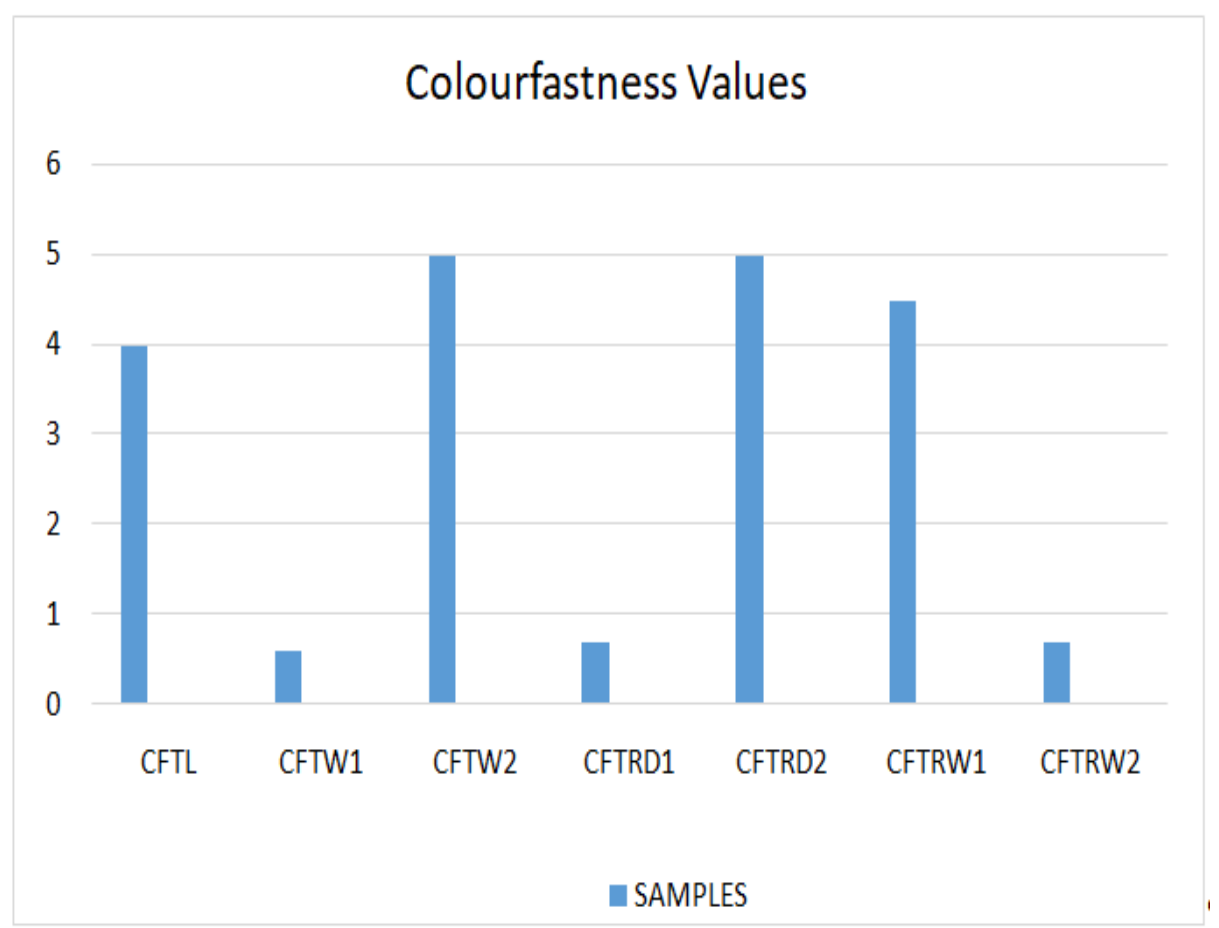

Figure 1

\section{CONCLUSIONS}

From the above study, it is concluded that the selected dye named Alkanna the tree bark layer has been used for the dyeing process which are highly suitable for bamboo fibre with Quercus Infectoria as the mordant. The pre-mordant technique are mostly suitable for regenerated fabric. These dyes are safe and are eco-friendly, therefore the use of the fibre also minimize the health concerns around the world which causes hazardous issues caused by use of synthetic dyes. These Natural Dyes gives some medical properties also. 


\section{REFERENCES}

1. Bhawa Ghorpade, Vandana Tiwari and Padma S Vankar March 2000, "Dyeing of linen fabric with canna flowers"

2. T. Bechtold, A. Turcanu,E. Gangberger, S. Geissler,J. Clean. Prod, 2003, 11, 499.

3. Mrijalini, K. Nazarpoor, L. Karimi, J. Clean. Prod.2011, 19, 1045.

4. T.L. Dawson, Colour. Technol.2009, 125, 61.

5. A.K. Samanta, P.Agarwal,Indian J. Fibre. Text. Res, 2009, 34, 384.

6. Natural Dyes and Eco friendly project (ITCOT),John Venture of ICICI, IDBI, IFCI, Chennai Pp4

7. Deepthi Gupta Dr and M.S Priyanka Gupta May2002, “ Natural Dyes having great potential, cloth -line” Pp27

8. K.Leon,D. Mery, F. Pedreschi, J. Leon, Color measurement in L*a*b* units from RGB digital images, 2006, 39, 1084. 
